\title{
EVALUACIÓN DE AGROECOSISTEMAS MEDIANTE INDICADORES DE SOSTENIBILIDAD EN SAN JOSÉ DE LAS LAJAS, PROVINCIA DE MAYABEQUE, CUBA
}

\author{
Liliana Silva-Santamaría \\ Omar Ramírez-Hernández (iD ${ }^{2}$
}

Recibido el 11 de noviembre de 2015, aprobado el 8 de mayo de 2016 y actualizado el

14 de diciembre de 2016

DOI: 10.17151/luaz.2017.44.8

\section{RESUMEN}

La presente investigación tiene como propósito la elaboración de un set de indicadores de sostenibilidad para tres (3) agroecosistemas localizados en el municipio de San José de Las Lajas (Cuba). Estos agroecosistemas fueron seleccionados por sus altos niveles de biodiversidad, por implementar técnicas agroecológicas, y por su fácil acceso y abierta disposición para participar en este proyecto. Metodológicamente se utilizaron principios de investigación acción participativa (IAP) y se analizaron muestras de agua y suelo en laboratorio. La construcción de los indicadores se hizo a partir de la metodología Marco para la evaluación de sistemas de manejo de recursos naturales incorporando indicadores de sustentabilidad (MESMIS) y en total se obtuvieron 34 indicadores para estimar la sostenibilidad de los agroecosistemas. De los resultados obtenidos se resalta que los tres agroecosistemas ostentan niveles de sostenibilidad relativamente altos $(>0.7)$, donde la finca La Joya es la que presenta el mayor índice (0.86) como resultado de las prácticas agroecológicas implementadas.

\section{PALABRAS CLAVE}

Agroecología, sostenibilidad, indicadores, conocimiento local, Cuba.

\section{AGROECOSYSTEMS ASSESSMENT BY SUSTAINABILITY INDICATORS IN SAN JOSÉ DE LAS LAJAS, MAYABEQUE PROVINCE, CUBA}

\begin{abstract}
The present research aims to elaborate a set of sustainability indicators for three (3) agroecosystems in the municipality of San José de las Lajas (Cuba). These agroecosystems were selected for its high levels of biodiversity, by they implement agroecological techniques and its easy access and open willingness to participate in this project. About the methodology, principles from Participatory Action Research (PAR) were used, and water and soil samples were analyzed. The construction of indicators was attained based on the Framework for the Evaluation of Natural Resource Management Systems Incorporating Sustainability Indicators (in Spanish, MESMIS) and, overall, 34 indicators were achieved to estimate the agroecosystem sustainability. From the results obtained, it should be emphasized that the three agroecosystems hold relative high levels of sustainability $(>0.7)$, where La Joya's farm shows the highest rate $(0.86)$ as a result of the agro-ecological practices implemented.
\end{abstract}

\section{KEY WORDS}

Agroecology, sustainability, indicators, local knowledge, Cuba. 


\section{INTRODUCCIÓN}

En la histórica y difícil tarea de producir alimentos para suplir las diversas necesidades de la sociedad humana, se han formulado numerosos modelos de desarrollo bajo premisas conceptuales varias, entre las cuales la agricultura moderna, o de altos insumos, ha sido sin duda la que ha alcanzado los mayores éxitos (en términos cuantitativos) a escala mundial.

Sin embargo, este modelo no ha podido solucionar los problemas alimentarios y socioeconómicos que flagelan a los países menos desarrollados, víctimas del franco deterioro de sus recursos naturales (Funes, 2007) y de la constante exposición a riesgos de origen tecnológico (Ramírez, 2009). Esto sugiere un cambio de concepción hacia una agricultura capaz de satisfacer las necesidades crecientes y cambiantes del ser humano, y de preservar y restaurar, al mismo tiempo, los recursos naturales y los agroecosistemas deteriorados (Leyva y Pohlan, 2005). Tales propósitos pudieran cumplirse promoviendo un acercamiento al desarrollo sostenible en el sector agrario, basado en técnicas agroecológicas capaces de producir sostenidamente, sin afectar de forma irreparable los recursos naturales y ecosistemas (Rosset, 1997; Funes et al., 2001; THREAD, 2005).

En este orden de ideas, la sostenibilidad de la agricultura está asociada a una serie de principios que incluyen aspectos sociales, ambientales y económicos del sistema (Masera y López-Ridaura, 2000; Sepúlveda, 2002; Red Leisa, 2007). En este sentido, la agricultura sostenible se define como un conjunto de sistemas integrados de producción agrícola, con mínima dependencia de altos insumos de energía en la forma de químicos sintéticos y métodos de cultivo, que mantienen su productividad y el ingreso de los productores, protegen el ambiente de la contaminación, fortalecen a las comunidades rurales y mantienen la diversidad ecológica y la estructura, fertilidad y productividad de los suelos a largo plazo (Pretty, 1995; Altieri y Nicholls, 2000). Además, se basa en la correcta toma de decisiones del agricultor sobre los múltiples recursos de los sistemas agrícolas: naturales, humanos, de capital y de producción (Müller, 1997; Masera et al., 1999; Sepúlveda, 2002).

En las últimas tres décadas ha surgido un especial interés dentro del movimiento agroecológico mundial por encontrar metodologías dirigidas a medir la sostenibilidad de los agroecosistemas (Leyva et al., 1999; Masera et al., 2000; FAO, 2004). Sin embargo, aún son escasas las investigaciones científicas profundas que adoptan este tipo de perspectivas $y$, aunque en general se han adelantado trabajos puntuales en diferentes regiones del mundo con aciertos plausibles (Leyva, 2000; Masera y LópezRidaura, 2000; FAO, 2004; Sarandón et al., 2006), los estudios más afamados parten de escenarios tradicionales que resultan insuficientes para establecer indicadores que caractericen, de forma eficiente y completa, los agroecosistemas. En la presente investigación se entiende por 'agroecosistema' aquella "comunidad de plantas y animales interactuando con su ambiente físico y químico que ha sido modificado para producir alimentos, fibra, combustible y otros productos para el consumo y procesamiento humano" (Altieri, 2002, 28).

Actualmente se cuenta con metodologías de distintos tipos y diseñadas para múltiples propósitos sustentadas en procesos participativos. Uno de los mayores avances en este tipo de metodologías son los obtenidos por el Grupo Interdisciplinario de Tecnología Rural Apropiada (GIRA), al desarrollar el Marco para la Evaluación de Sistemas de Manejo de recursos naturales incorporando Indicadores de 
Sustentabilidad (MESMIS), el cual constituye una propuesta de evaluación que sirve como punto de apoyo para hacer operativo el concepto de sostenibilidad en la búsqueda de un desarrollo económico-social equitativo y ambientalmente sano de las comunidades rurales (Masera et al., 1999; Astier et al., 2002). Las principales características de esta metodología se describen en Astier et al. (2007).

Ahora bien, en Cuba, los principios agroecológicos (como buscar soluciones ecológicas al control de plagas, enfermedades y malezas, e implementar técnicas ecológicas para el laboreo y la conservación de suelos) comenzaron a aplicarse en la investigación desde la década de los 70 y se fortalecieron en los años 80 , pero no fue hasta la etapa conocida como "periodo especial" ${ }^{3}$ que se iniciaron diversas transformaciones en el sector agropecuario, con miras a convertir la agricultura en una actividad sostenible, a raíz de la necesidad de producir, con menos insumos, en todas las ramas de la economía nacional (Funes, 2007; Jiménez, 2007; Rodríguez, 2007).

Cuba cuenta con información de diversas investigaciones realizadas bajo principios agroecológicos, tanto en los centros experimentales como en escenarios campesinos, privados y cooperativos. Dichas dinámicas han incentivado el desarrollo de investigaciones orientadas a la elaboración de metodologías de estudio para un mayor acercamiento al desarrollo sostenible (Socorro, 2002; Pérez, 2003; Leyva y Pohlan, 2005). Esto ha permitido establecer propuestas integrales de desarrollo, dirigidas al enriquecimiento de la agrodiversidad y la introducción de alternativas agroecológicas. No obstante, gran parte de estos estudios han desconocido la participación de los principales actores del proceso productivo y su capacitación actualizada en los nuevos adelantos de la ciencia y la técnica (Leyva y Pohlan, 2005).

De esta forma, se evidencia que existe aún carencia de investigaciones que analicen los agroecosistemas, desde una visión holística del desarrollo agrario sostenible, a partir de la visión in situ de los actores involucrados. Además, se puede inferir que hay limitados estudios que, mediante indicadores, aporten información sobre el estado de los agroecosistemas en San José de Las Lajas, capaces de visualizar el acercamiento necesario a la sostenibilidad en correspondencia con los valores utilitarios de la agrodiversidad.

Por lo anterior, la presente investigación intenta avanzar en ambos sentidos, al trazar como objetivo evaluar las tendencias de sostenibilidad de tres agroecosistemas localizados en el municipio de San José de Las Lajas (Cuba), a través de la medición de indicadores económicos, ecológicos y socioculturales.

\section{Materiales y método}

\subsection{Descripción del área de estudio}

El trabajo se desarrolló en tres fincas del municipio de San José de Las Lajas, seleccionadas por sus altos niveles de biodiversidad, por implementar técnicas agroecológicas, y por su fácil acceso y abierta disposición para participar en la investigación. Las principales características de estas fincas se presentan en el Cuadro 1. 
Cuadro 1. Características de las fincas objeto de estudio

\begin{tabular}{|c|c|c|c|}
\hline Nombre & Localización & $\begin{array}{l}\text { Área } \\
(\mathrm{Ha})\end{array}$ & $\begin{array}{c}\text { Núcleo } \\
\text { familiar } \\
\text { (\# personas) }\end{array}$ \\
\hline La Chivería & $\begin{array}{l}\text { Autopista nacional, kilómetro } 15, \\
\text { Consejo Popular Zaragoza }\end{array}$ & 6 & 4 \\
\hline $\begin{array}{c}\text { Patio } \\
\text { Integral La } \\
\text { Joya }\end{array}$ & $\begin{array}{l}\text { Reparto La Victoria, calle } 34 \text { No. } \\
2902 \text {, circunscripción No. } 67 \text {, del } \\
\text { Consejo Popular Norte }\end{array}$ & 0.32 & 4 \\
\hline El Encanto & $\begin{array}{l}\text { A la salida de San Antonio de las } \\
\text { Vegas, carretera a Melena del Sur, } \\
\text { Consejo Popular San Antonio de } \\
\text { las Vegas }\end{array}$ & 14.2 & 7 \\
\hline & Total & 20.52 & 15 \\
\hline
\end{tabular}

El municipio está ubicado a los $22^{\circ} 58^{\prime} 4$ " Norte y $82^{\circ} 9^{\prime} 21^{\prime \prime}$ Oeste (Figura 1). Tiene un clima tropical húmedo con precipitaciones que superan los $1500 \mathrm{~mm}$ anuales, una temperatura media anual de $23.9^{\circ} \mathrm{C}$ y una humedad relativa del $80 \%$. El $76 \%$ del área es suelo de fondo agrícola, del cual el $54 \%$ es cultivable y el $22 \%$ restante está en conflicto de uso, fundamentalmente área ganadera, y un $13 \%$ corresponde a áreas forestales (Oficina Nacional de Estadística, 2010).

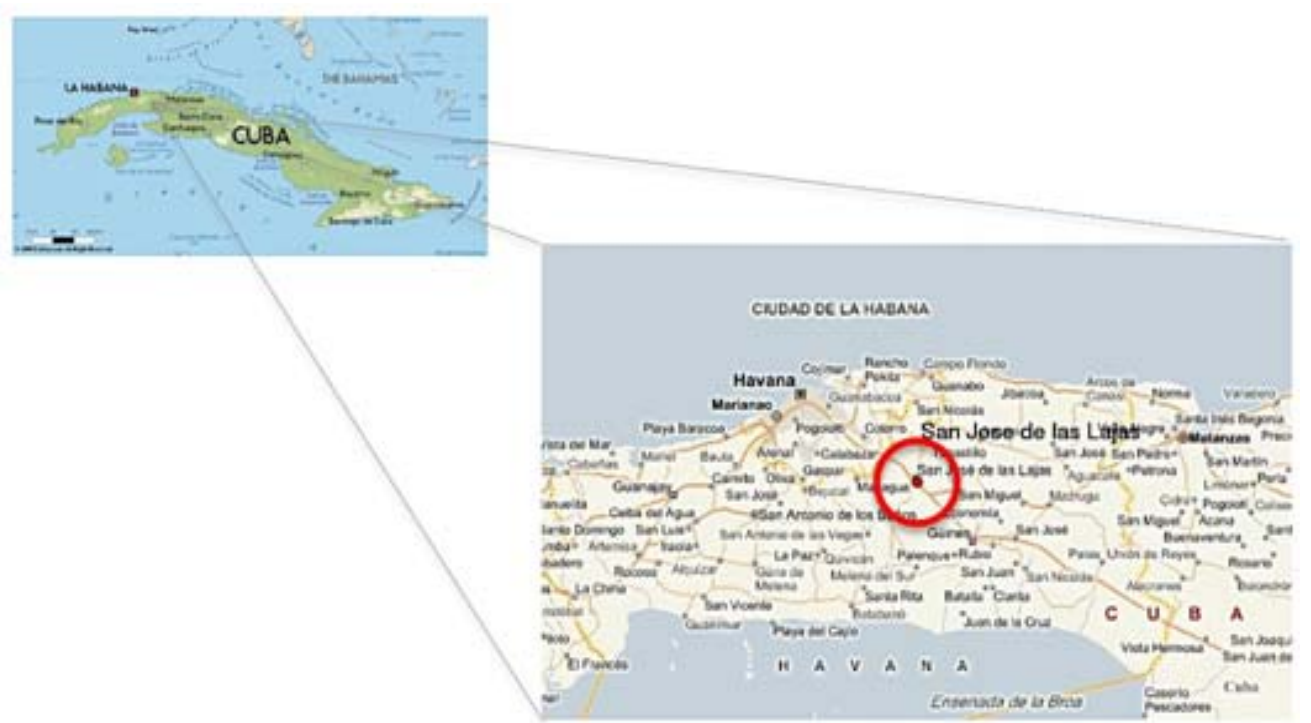

Fuente: http://es.weather-forecast.com

Figura 1. Ubicación del área de estudio 


\subsection{Aspectos metodológicos}

La metodología de estudio se fundamentó en los principios de la investigación-acciónparticipativa (IAP) y se diseñó a partir de la integración de métodos de análisis multicriterio y herramientas para el estudio y la evaluación de la sostenibilidad (Masera y López-Ridaura, 2000; Sepúlveda, 2002; FAO, 2004; Venegas, 2004).

Para diagnosticar el estado de los sistemas agrícolas fue necesaria la construcción de indicadores de sostenibilidad, para lo cual se aplicó la metodología MESMIS. Ésta es una herramienta innovadora para avanzar en la evaluación de la sustentabilidad de sistemas rurales, a partir de un enfoque cíclico, sistemático y multiescalar. La sustentabilidad, en esta metodología, se concibe de manera dinámica y específica de un determinado contexto socioambiental, y se analiza, de forma participativa, a partir de la interacción de múltiples elementos que no pueden estudiarse de manera aislada (Astier et al., 2008). En la Figura 2 se presenta el ciclo de evaluación MESMIS seguido en el presente trabajo.

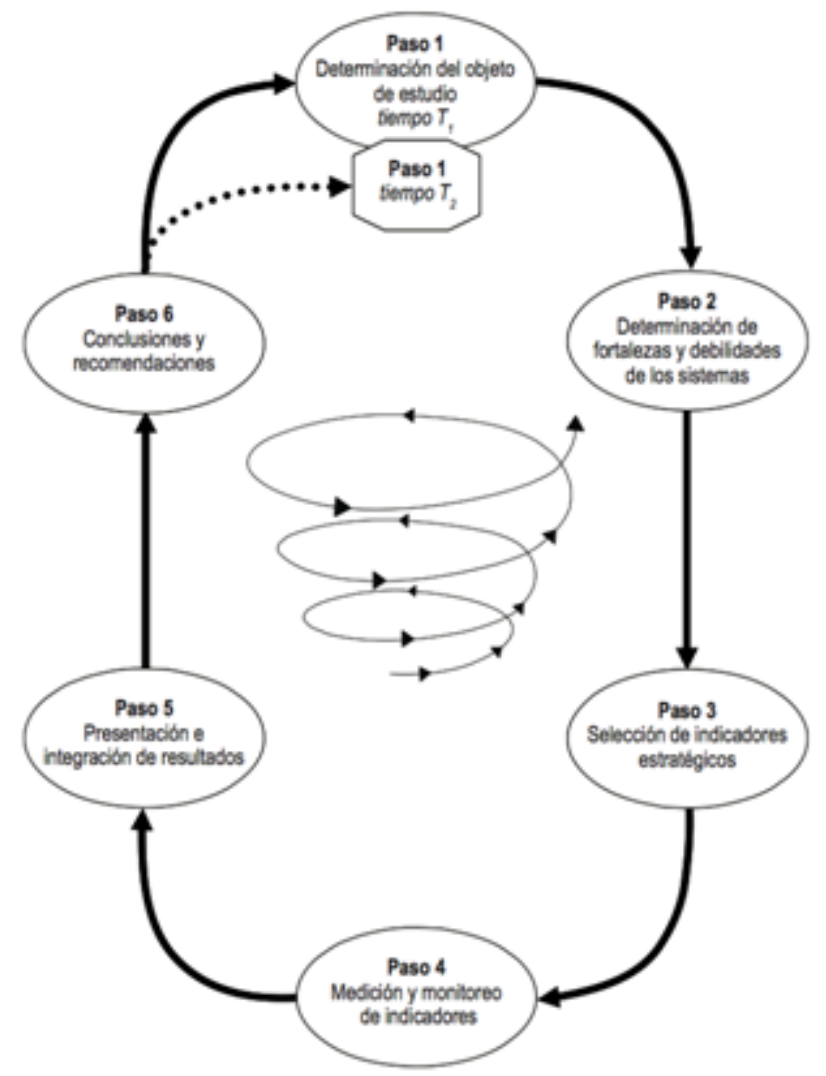

Fuente: Masera et al., 1999.

Figura 2. Ciclo de evaluación en MESMIS

En el primer paso se definió como objeto de estudio la evaluación de la sustentabilidad de tres agroecosistemas.

En el segundo paso se identificaron las fortalezas y debilidades de cada una de las fincas. Dicho diagnóstico se desarrolló sobre la base metodológica del diagnóstico rural participativo (DRP) (Schönhuth y Kievelitz, 1994). Para obtener la información necesaria y analizar cada agroecosistema en sus dimensiones económica, ecológica y sociocultural, se combinaron diversas herramientas tales como: recorridos 
exploratorios y entrevistas informales, encuestas formales, diálogos semiestructurados y observaciones (Geilfus, 2002), realizadas entre enero y septiembre de 2013.

Como parte del reconocimiento de las fortalezas y debilidades de la zona de estudio, se midieron experimentalmente los principales parámetros que describen la calidad química del agua para uso doméstico y las principales propiedades químicas del suelo. Para el primer caso se analizó la dureza total expresada como $\mathrm{CaCO} 3$, el contenido de $\mathrm{Ca}, \mathrm{Mg}, \mathrm{Cl}$ y el $\mathrm{pH}$. Esto se hizo siguiendo las técnicas establecidas según la normatividad cubana (MINSAP, 2001), en los laboratorios de Agua y Suelos del Instituto Nacional de Ciencias Agrícolas (INCA), adscrito a la Universidad Agraria de La Habana (UNAH). Para el segundo caso, se seleccionaron entre tres y cinco muestras de suelo a una profundidad de $0-30 \mathrm{~cm}$. La cantidad de muestras fue correspondiente con el tamaño del área (fluctuó entre 0.25 y 6.25 ha) y los análisis se realizaron en el laboratorio de suelos del INCA por profesionales del área, quienes determinaron los valores de $\mathrm{Na}, \mathrm{K}, \mathrm{Ca}, \mathrm{Mg}, \mathrm{P}, \mathrm{MO}$ y $\mathrm{pH}$. Las muestras de agua y suelo se tomaron, una sola vez, entre marzo y abril de 2013, y se hizo un solo análisis de laboratorio en mayo del mismo año.

En el tercer paso se definieron los indicadores estratégicos de sustentabilidad, para lo cual se siguieron tres fases (Astier et al., 2008): i) Selección de los 'atributos' de sustentabilidad (características que sirven de guía del análisis y cubren los aspectos más relevantes del sistema); ii) Identificación de los criterios de diagnóstico (describen los atributos mediante reglas que gobiernan los juicios de sustentabilidad); y iii) Definición de los indicadores de sustentabilidad (variables que aportan información relevante para un criterio de diagnóstico).

En este trabajo se identificaron siete atributos de sustentabilidad que representan, según Astier et al. (2008), propiedades sistémicas fundamentales: productividad, estabilidad, confiabilidad, resiliencia, adaptabilidad, equidad y autogestión (para una definición detallada de cada uno de ellos, ver Masera et al., 1999).

La definición de los criterios de diagnóstico y sus respectivos indicadores se hizo de forma participativa, de tal manera que los productores seleccionaron, tras un proceso de ponderación, aquellos que representaban mejor la sostenibilidad del agroecosistema. Se tuvo en cuenta: i) el nivel de representatividad de los atributos; ii) la confiabilidad de la información y el acceso a la misma; iii) la facilidad de la medición de los indicadores; y iv) la necesidad de considerar todas las áreas de evaluación (ecológica, económica y social). Se definieron 13 criterios de diagnóstico y 34 indicadores (Cuadro 2). 
Cuadro 2. Fases para la definición de indicadores de sustentabilidad

\begin{tabular}{|c|c|c|c|}
\hline Dimensión & Componente & $\begin{array}{l}\text { Criterio de } \\
\text { diagnóstico }\end{array}$ & Indicador \\
\hline \multirow{14}{*}{$\begin{array}{l}\text { Biofisica- } \\
\text { Ambiental } \\
\text { (Ecológica) }\end{array}$} & \multirow{14}{*}{$\begin{array}{l}\text { Estabilidad } \\
\text { Resiliencia } \\
\text { Confiabilidad }\end{array}$} & \multirow{2}{*}{$\begin{array}{c}\text { Visión } \\
\text { integradora }\end{array}$} & Integración de uso de la tierra \\
\hline & & & $\begin{array}{l}\text { Capacidad productiva del } \\
\text { agroecosistema }\end{array}$ \\
\hline & & \multirow{3}{*}{ Suelos } & Fertilidad del suelo \\
\hline & & & $\begin{array}{l}\text { Medida en que se evita la } \\
\text { degradación }\end{array}$ \\
\hline & & & Productividad \\
\hline & & \multirow{3}{*}{ Clime } & Tecnología del manejo del suelo \\
\hline & & & $\begin{array}{l}\text { Combinacióny distribución de los } \\
\text { elementos climáticos }\end{array}$ \\
\hline & & & $\begin{array}{l}\text { Magnitud de las afectaciones por } \\
\text { eventos meteoroló gicos severos }\end{array}$ \\
\hline & & \multirow{3}{*}{ Agues } & $\begin{array}{l}\text { Manejo racional del recurso agua } \\
\text { y la cuenca }\end{array}$ \\
\hline & & & $\begin{array}{l}\text { Disponibilidad y eficiencia de } \\
\text { utilización }\end{array}$ \\
\hline & & & $\begin{array}{l}\text { Competencia entre consumo } \\
\text { humano/agricultura }\end{array}$ \\
\hline & & \multirow{3}{*}{ Biodiversidad } & Diversidad en el agroecosistema \\
\hline & & & Diversidad de especies \\
\hline & & & Diversidad genética \\
\hline
\end{tabular}




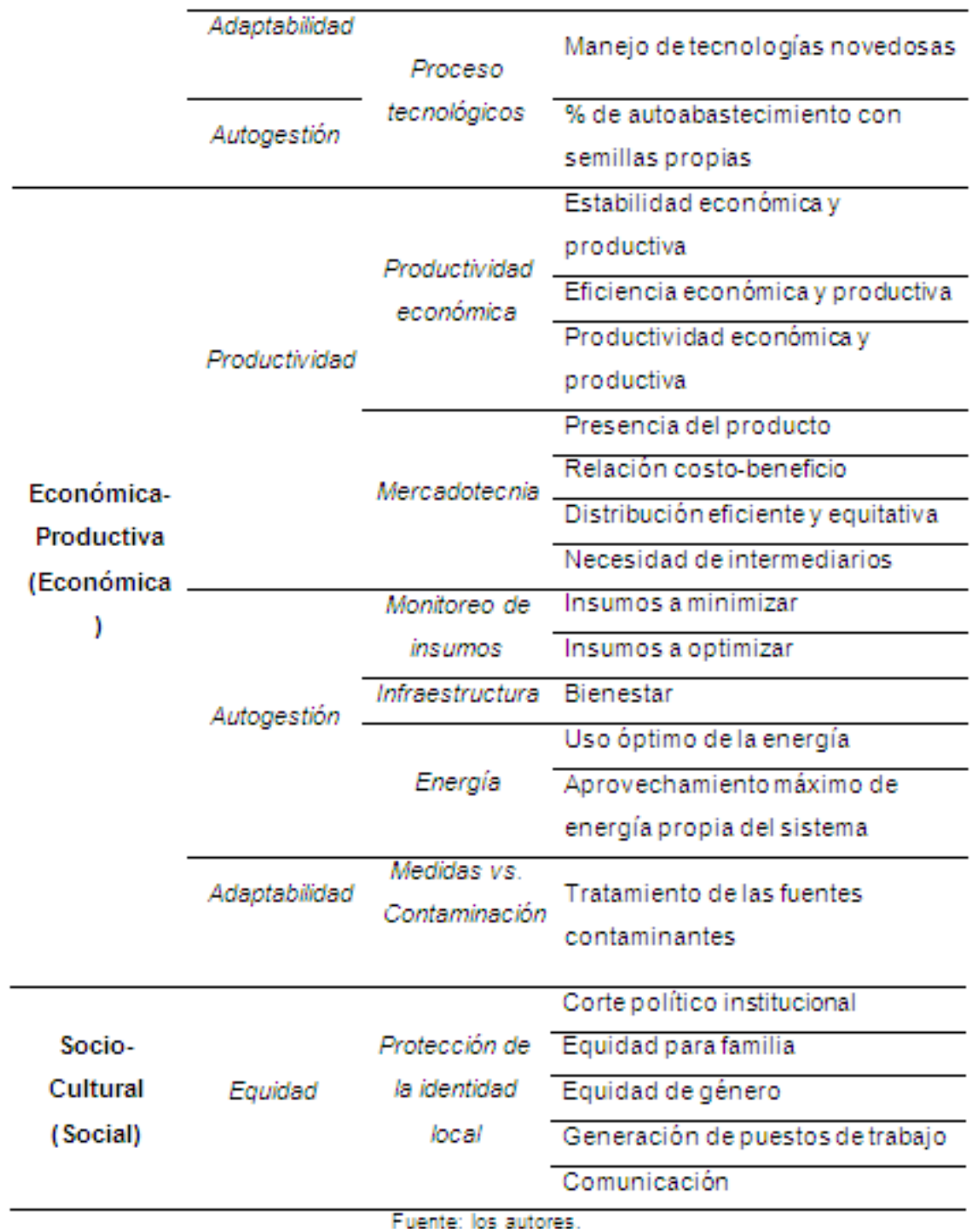

En el cuarto paso (medición y monitoreo) se utilizó (de forma adaptada) la metodología propuesta por Reyes y Ammour (1997), basada en una secuencia de términos y ecuaciones matemáticas para determinar el valor de los indicadores, el valor de los criterios de diagnóstico y el índice general de sostenibilidad.

- Valor de los indicadores (VI):

Teniendo en cuenta que los indicadores seleccionados tienen diferentes unidades de medición (porcentajes, valores monetarios, índices y datos cualitativos), lo cual no permite la comparación directa entre ellos, se construyó una escala estandarizada (valor de juicio) que representa el valor de los indicadores con relación a la situación deseable. Para ello, se definieron condiciones máximas y mínimas, según recomendaciones de López-Ridaura et al. (2002) y Moreno et al. (2006). En este caso, teniendo en cuenta las características de los agroecosistemas, se le asignó un valor entre 0 y 10 a cada indicador, en cinco rangos de valores, mediante un proceso interactivo con los facilitadores y actores involucrados en la investigación. La escala estandarizada permitió organizar toda la información y convertir los distintos indicadores en uno homogéneo. Por limitación de espacio no se presentan las características de evaluación de cada uno de los 34 indicadores, pero, a modo de ejemplo, en el Cuadro 3se presentan los rangos y criterios de valoración de tres de ellos. 
Cuadro 3. Ejemplos de rangos y criterios de evaluación

\begin{tabular}{|c|c|}
\hline \multicolumn{2}{|r|}{ Fertilidad del suelo } \\
\hline Valor & Caracteristica \\
\hline $0-2$ & $\begin{array}{l}\text { Crece poco lo que se cultiva, color amarillo, contenido de materia orgánica } \\
<1 \%\end{array}$ \\
\hline 3.4 & Contenido de materia orgánica entre 1 y $2 \%$ \\
\hline $5-6$ & $\begin{array}{l}\text { Crece bien lo que se cultiva, color oscuro claro, contenido de materia } \\
\text { orgánica entre } 2 \text { y } 3 \%\end{array}$ \\
\hline $7-8$ & $\begin{array}{l}\text { Color oscuro, aspecto del cultivo vigoroso, contenido de materia orgánica } \\
\text { entre } 3 \text { y } 4 \%\end{array}$ \\
\hline $9-10$ & Contenido de materia orgánica $>4 \%$ \\
\hline \multicolumn{2}{|r|}{ Insumos a optimizar } \\
\hline Valor & Caracteristica \\
\hline $0-2$ & Más del $70 \%$ de los insumos totales usados son externos \\
\hline $3-4$ & $\begin{array}{l}\text { Entre el } 60-70 \% \text { de los insumos son externos (fertilizantes, plaguicidas, } \\
\text { combustibles y semillas) }\end{array}$ \\
\hline $5-6$ & $\begin{array}{l}\text { Entre el } 40-50 \% \text { de los insumos son externos (fertilizantes, plaguicidas y } \\
\text { combustibles) }\end{array}$ \\
\hline $7-8$ & Entre el $20-30 \%$ de los insumos son externos (plaguicidas y combustibles) \\
\hline 9-10 & $\begin{array}{l}\text { Mínima dependencia de recursos externos (menos del } 20 \% \text { ), solamente } \\
\text { combustible diésel y en pequeña proporción }\end{array}$ \\
\hline \multicolumn{2}{|r|}{$\%$ de autoabastecimiento con semillas propias } \\
\hline Valor & Característica \\
\hline 0.2 & No produce sus semillas \\
\hline 3.4 & Produce hasta el $40 \%$ de las semillas que necesita \\
\hline $5 \cdot 6$ & Produce entre el 40 y el $60 \%$ de las semillas que necesita \\
\hline 7.8 & $\begin{array}{l}\text { Produce hasta el } 80 \% \text { de las semillas que necesita y cuenta con buenas } \\
\text { condiciones para su conservación }\end{array}$ \\
\hline 9.10 & $\begin{array}{l}\text { Produce las semillas que necesita, presta servicio a otros productores y } \\
\text { cuenta con buenas condiciones para su conservación }\end{array}$ \\
\hline
\end{tabular}

- Valor de los criterios de diagnóstico (VCD)

$$
V C D=\frac{\sum(V I)}{S}[\text { Ecuación 1] }
$$

Donde $S$ es el número de indicadores que conforman cada criterio de diagnóstico.

\section{- Índice general de sostenibilidad (IGS)}




$$
I G S=\frac{\sum(V C D)}{N}[\text { Ecuación 2] }
$$

Donde $\mathrm{N}$ es el número de criterios de diagnóstico.

En el quinto paso de la metodología MESMIS se utilizó el diagrama tipo "ameba" para presentar el valor de los indicadores, de cada uno de los agroecosistemas, agrupados en las dimensiones ecológica, económica y social. Finalmente, se graficaron los IGS obtenidos y se procedió a hacer un análisis comparativo de los niveles de sostenibilidad.

Por último, como parte del sexto paso, se procedió a presentar las conclusiones y postular algunas recomendaciones generales.

\section{RESULTADOS Y DISCUSIÓN}

\subsection{Fortalezas y debilidades del área de estudio}

El $55.7 \%$ de las personas de los agroecosistemas estudiados se encuentra dentro del rango de edad laboral (18-60 años), clasificado como fuerza productiva I (FP-I). Estos datos indican una alta disponibilidad de recursos humanos.

El diagnóstico mostró que no existen problemas referentes a los principales servicios sociales y calidad de vida. El $100 \%$ de las familias tienen acceso a la salud pública y a la educación de forma gratuita. Además, para todas las edades, tanto en el área rural como urbana, se cuenta con oportunidades para elevar el nivel escolar desde la primaria hasta la universidad, lo cual está priorizado por los nuevos programas estatales de educación.

Las tres familias objeto de este estudio poseen viviendas propias con servicios de agua potable y electricidad, y tienen los equipos electrodomésticos imprescindibles proporcionados a través de programas sociales del Estado.

\section{Disponibilidad y calidad de agua}

Para el uso doméstico, el agua se obtiene a través de la red pública y se encuentra entre los parámetros establecidos por la bibliografía nacional como agua de buena calidad para el uso humano. Esto se pudo comprobar mediante el análisis químico adelantado en esta investigación (Cuadro 4). 
Cuadro 4. Principales parámetros de la calidad química del agua

\begin{tabular}{cccc}
\hline Componentes & \multirow{2}{*}{ Resultados (mg/l) } & \multicolumn{2}{c}{ Normas cubanas } \\
\cline { 3 - 4 } & & CMD (mg/l) & CMA \\
\hline Sales solubles totales & 342 & - & - \\
Dureza total (como CaCO3) & 20 & 100 & 400 \\
Cloruro & 198 & 200 & 250 \\
Calcio & 82 & 75 & 200 \\
Magnesio & 15 & 30 & 150 \\
$p H$ & 7.4 & $6.8-7.1$ & - \\
Conductividad eléctrica CE & 0.56 & $0.53-$ & - \\
(mm/cm) & \multicolumn{4}{c}{$0.65^{*}$} & \\
\hline CMD: Concentración Máxima Deseable; CMA: Concentración Máxima Admisible. \\
*Relacionada con TDS - Total de Sólidos Disueltos - la cantidad total de sólidos \\
disueltos en el agua, principalmente de las sales minerales. \\
\multicolumn{4}{c}{ Fuente: los autores. }
\end{tabular}

Se infiere, además, que el agua tiene la calidad biológica requerida, teniendo en cuenta que el Instituto Nacional de Recursos Hidráulicos lleva un programa de control periódico, según las normas establecidas para el control sanitario en Cuba.

Por otra parte, el agua que se utiliza para el riego proviene principalmente de pozos subterráneos y el análisis de disponibilidad manifestó que el $67 \%$ de las fincas posee pozos particulares, permitiéndoles satisfacer el $70 \%$ de las necesidades de riego. El otro $33 \%$ de las fincas carece de riego para sus cultivos, lo cual constituye una problemática para el desarrollo sostenible de la comunidad.

\section{Estado del recurso natural suelo}

En la comunidad predominan los suelos ferralíticos rojos compactados y fersialíticos pardos rojizos lixiviados, según la Nueva Versión de Clasificación Genética de los Suelos de Cuba (Hernández et al., 2006), los que se corresponden con Nitisol Ródico y Luvisol Crómico respectivamente, según World Reference Base (Deckers et al., 1998). La topografía es llana y el suelo se caracteriza por tener una profundidad efectiva promedio de $50 \mathrm{~cm}$. Aunque en algunos casos se consideran pocos profundos, no constituyen una limitante para los cultivos que se establecen en el territorio.

Las principales propiedades químicas medidas en este trabajo (Cuadro 5) se encuentran entre los parámetros medios permisibles para que se desarrollen los principales cultivos agrícolas de la zona. La materia orgánica tiene valores entre $3 \%$ y $4 \%$. 
Cuadro 5. Principales propiedades químicas del suelo

\begin{tabular}{|c|c|c|c|c|c|c|}
\hline \multicolumn{4}{|c|}{ Expresada en $\left(\mathrm{cmol} . \mathrm{Kg}^{-1}\right)$} & \multirow{2}{*}{$P(p p m)$} & \multirow{2}{*}{ Materia Orgánica (\%) } & \multirow{2}{*}{$\mathrm{pH}\left(\mathrm{H}_{2} \mathrm{O}\right)$} \\
\hline $\mathrm{Na}$ & $\mathrm{K}^{+}$ & $\mathrm{Ca}^{2+}$ & $\mathrm{Mg}^{2+}$ & & & \\
\hline 0.22 & 0.53 & 33.25 & 8.06 & 43.33 & 3.25 & 7.59 \\
\hline
\end{tabular}

\section{Agrobiodiversidad}

La agrobiodiversidad manejada por los productores varía entre un sistema y otro, lo cual está influido por las características propias de cada agroecosistema y la especialización y los niveles de preferencias de los productores. Se observa que los cultivos más comunes son los relacionados directamente con las costumbres alimenticias locales y la generación de ingresos (Cuadro 6).

Cuadro 6. Principales componentes de la agrobiodiversidad en la comunidad

\begin{tabular}{cll}
\hline \multicolumn{2}{c}{ Componente } & \multicolumn{1}{c}{ Descripción } \\
\hline \multirow{4}{*}{ Agrícola } & Granos y cereales & Maíz, arroz, soya, frijol \\
\cline { 2 - 3 } & Raíces y tubérculos & Malanga, boniato, yuca, zanahoria \\
\cline { 2 - 3 } & Oleaginosas & Girasol, maní \\
\cline { 2 - 3 } & Frutas & Guayaba, mango, papaya, mamey \\
\cline { 2 - 2 } & Hortalizas & Tomate, ají, cebolla, ajo, col \\
\hline & Pecuario & Aves de corral, cerdos, cabras, vacas, bueyes \\
\hline
\end{tabular}

\section{Situación económico-productiva}

La base económica de los agroecosistemas estudiados está diseñada en función del manejo de la agrobiodiversidad. De ahí que la distribución del área favorece la producción agrícola de cultivos rotativos, tanto para el mercado como para el autoabastecimiento de las familias, seguido por cultivos perennes, áreas de pastos, áreas en barbecho, áreas destinadas a la producción de abonos orgánicos, semilleros, viveros, entre otros (Figura 3). 


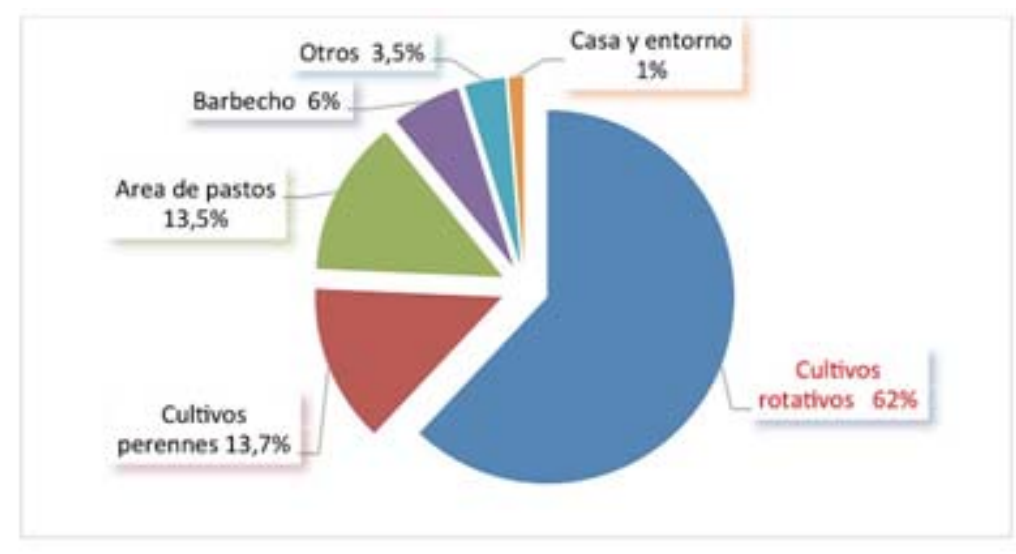

Fuente: los autores.

Figura 3. Distribución de uso del suelo de los agroecosistemas estudiados

Los productores están favorecidos por la situación económica del país, donde todo lo que se produce en términos de alimentación humana tiene mercado. De acuerdo con esto, los productores obtienen ingresos estimables para sus familias y en general poseen un nivel de vida con el que cubren satisfactoriamente todas sus necesidades, aunque no informan sobre sus ganancias anuales.

\subsection{Finca La Chivería}

En el Cuadro 7 se presentan las principales características ecológicas. 
Cuadro 7. Aspectos ecológicos de la finca La Chivería

\begin{tabular}{|c|c|}
\hline Diversidad & $\begin{array}{l}\text { Cuenta con más de } 30 \text { especies de cultivos agrícolas (hortalizas, } \\
\text { viandas, granos y frutales). Produce sus propias semillas y se ha } \\
\text { convertido en un importante banco de semillas en la localidad. }\end{array}$ \\
\hline Suelo & $\begin{array}{l}\text { Se diferencian dos texturas y estructuras: un área granular suelta } \\
\text { de buen drenaje superficial e interno y otra prismática y plástica } \\
\text { propia de un suelo pesado de drenaje interno deficiente. Combina } \\
\text { tracción animal y mecanización. }\end{array}$ \\
\hline Agua & $\begin{array}{l}\text { Tiene dos fuentes de abastecimiento: i) Pozo con una turbina } \\
\text { acoplada a un trasformador de } 220 \mathrm{v} \text {, y ii) Turbina con motor diésel. }\end{array}$ \\
\hline $\begin{array}{l}\text { Subsistema } \\
\text { agricola }\end{array}$ & $\begin{array}{l}\text { Incorpora plantas y árboles (barreras vivas) como: coco, ciruela, } \\
\text { anón, cítricos y marabú. El abono es orgánico y consiste en } \\
\text { estiércol vacuno y humus de lombriz. Se aplica muy poco } \\
\text { fertilizante químico, solo en algunos cultivos en su fase crítica. Ej. } \\
\text { Frijol (1/4 litro de urea por cada } 15 \text { - } 20 \text { litros de agua). }\end{array}$ \\
\hline $\begin{array}{l}\text { Subsistema } \\
\text { pecuario }\end{array}$ & $\begin{array}{l}\text { Tiene un total de seis especies: conejos, gallinas, cabras, cerdos, } \\
\text { vacas y bueyes. Se mantiene siempre una reserva de animales } \\
\text { para asegurar el aporte proteínico de la familia. Los desechos de } \\
\text { los animales son utilizados para la fertilización de sus cultivos. }\end{array}$ \\
\hline
\end{tabular}

En esta finca se resalta la biodiversidad, especialmente en los cultivos. Se siembra girasol para cercar los cultivos de soya y fríjol, principalmente, para que atraiga a los insectos que podrían perjudicarlos. Las flores cardona y flor de muerto se siembran también, ya que sirven como repelente natural de insectos. Para mantener la finca, el productor cuenta con un tractor, arado de disco, un multiarado (que utiliza además como surcador - cultivador), una yunta de bueyes e implementos de trabajo manual.

Según el productor, la finca es rentable económicamente, aunque no realiza una contabilización estricta de la producción. Según las apreciaciones de la familia, las ganancias representan alrededor de 30 centavos por peso de producción. Es decir, por cada peso de producción obtenido se requiere una inversión de 0.70 centavos.

Aunque esta finca se destaca por la producción de semillas en general, éste no es un rubro importante de comercialización, ya que gran parte de la producción se destina a la conservación para la propia finca. Algunos gastos del sistema son: 20 pesos a cada trabajador contratado en picos de cosecha, combustible diésel, preparación del suelo, transporte de materia orgánica, comercialización de la cosecha y compra de biofertilizantes. En el Cuadro 8 se presentan los indicadores de sostenibilidad de la finca La Chivería. 
Cuadro 8. Indicadores de sostenibilidad de La Chivería

\begin{tabular}{|c|c|c|c|}
\hline Dimensión & $\begin{array}{l}\text { Criterio de } \\
\text { diagnóstico }\end{array}$ & Indicador & $\begin{array}{l}\text { Valor del } \\
\text { indicador }\end{array}$ \\
\hline \multirow{14}{*}{$\begin{array}{l}\text { Biofisica- } \\
\text { Ambiental } \\
\text { (Ecológica) }\end{array}$} & Mánín & Integración de uso de la tierra & 0.7 \\
\hline & integradora & $\begin{array}{l}\text { Capacidad productiva del } \\
\text { agroecosistema }\end{array}$ & 0.7 \\
\hline & \multirow{3}{*}{ Suelos } & Fertilidad del suelo & 0.8 \\
\hline & & Medida en que se evita la degradación & 0.9 \\
\hline & & Productividad & 0.8 \\
\hline & \multirow{3}{*}{ Clima } & Tecnología del manejo del suelo & 0.7 \\
\hline & & $\begin{array}{l}\text { Combinacióny distribución de los } \\
\text { elementos climáticos }\end{array}$ & 0.7 \\
\hline & & $\begin{array}{l}\text { Magnitud de las afectaciones por } \\
\text { eventos meteorológicos severos }\end{array}$ & 0.7 \\
\hline & \multirow{3}{*}{ Aguas } & $\begin{array}{l}\text { Manejo racional del recurso agua y la } \\
\text { cuenca }\end{array}$ & 0.8 \\
\hline & & $\begin{array}{l}\text { Disponibilidad y eficiencia de } \\
\text { utilización }\end{array}$ & 0.8 \\
\hline & & $\begin{array}{l}\text { Competencia entre consumo humanol } \\
\text { agricultura }\end{array}$ & 0.6 \\
\hline & \multirow{3}{*}{ Biodiversidad } & Diversidad en el agroecosistema & 0.7 \\
\hline & & Diversidad de especies & 0.7 \\
\hline & & Diversidad genética & 0.8 \\
\hline
\end{tabular}




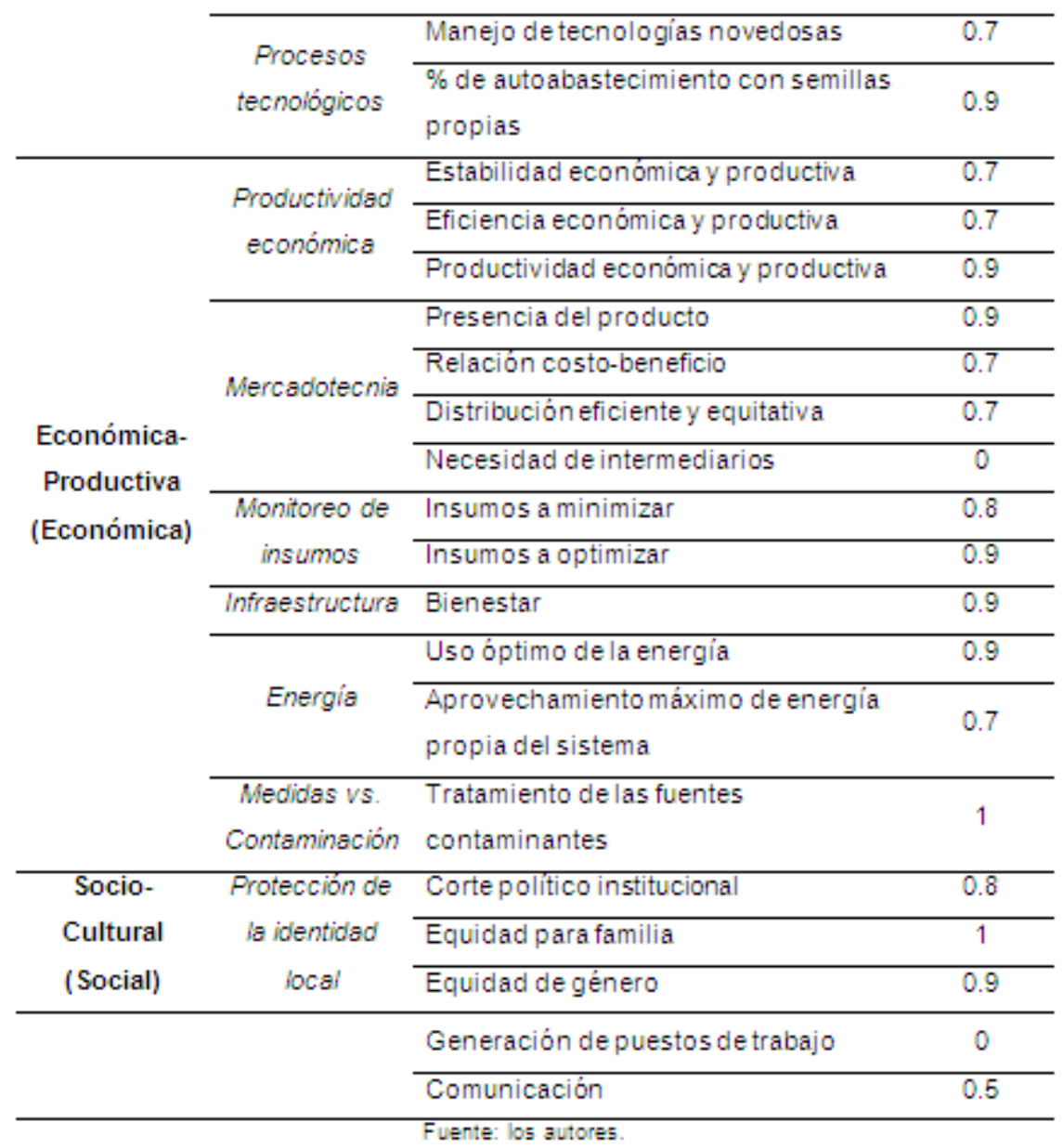

En la Figura 4 se presentan los resultados mediante la técnica gráfica "ameba" de la finca La Chivería. 


\section{DIMENSIÓN ECOLÓGICA}

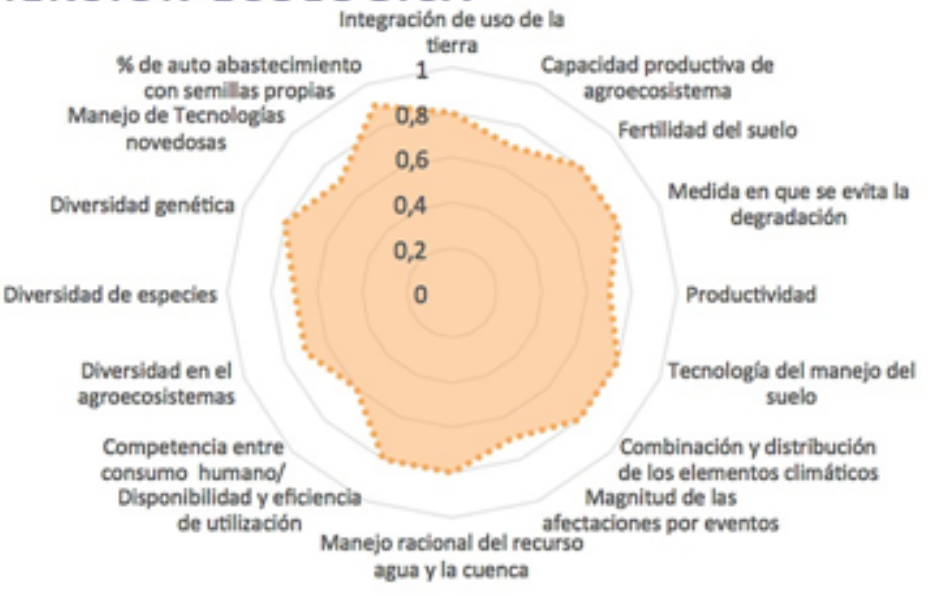

\section{DIMENSIÓN ECONÓMICA}

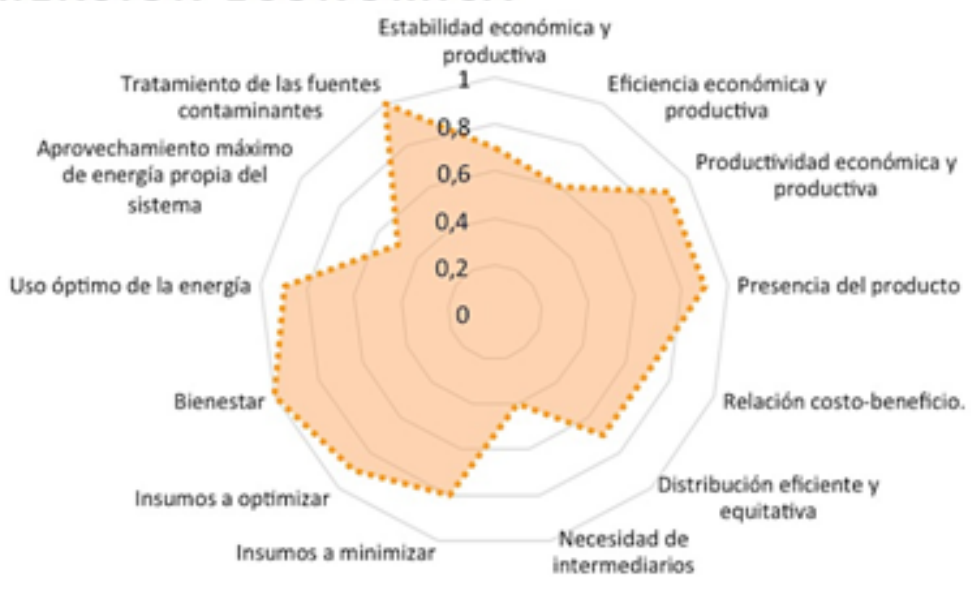

\section{DIMENSIÓN SOCIAL}

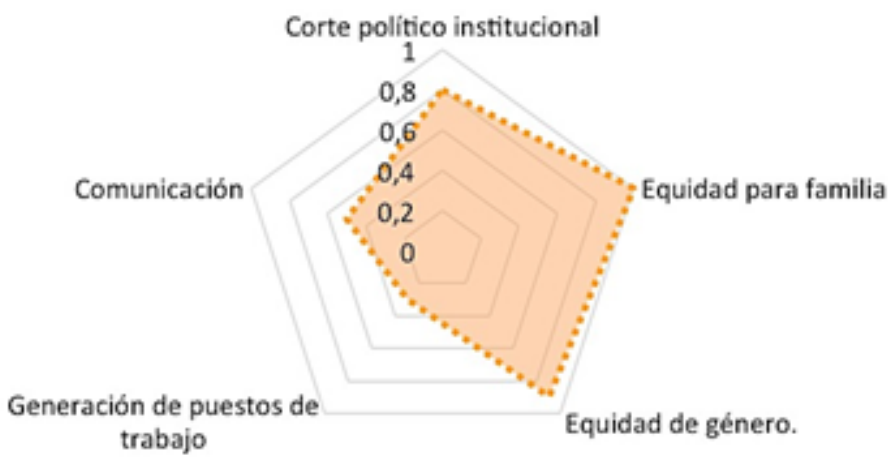

Fuente: los autores.

Figura 4. Tendencias de la sostenibilidad del agroecosistema La Chivería

Las gráficas reflejan que esta finca debe profundizar en los procesos de integración de las dimensiones ecológica y económico- productivo, por medio de la diversificación con 
animales, lo que potenciaría el reciclado de nutrientes. Debe aprovechar, además, las energías alternativas para reducir el consumo de diésel.

Por otro lado, debido a su tamaño y al fuerte apoyo familiar, la finca no genera empleo. No obstante, apoya a otros productores regalando semillas de alto valor $y$ productividad.

La debilidad más marcada de este agroecosistema es el hecho de no tener registros contables, ni tener reconocido su papel como productor de semillas, lo que impide que sean certificadas.

En la dimensión ecológica se observa el interés de esta familia productora por buscar, mediante la diversidad de especies, su transformación hacia la sostenibilidad. La guía acertada del jefe de familia y el entusiasmo y fuerza de voluntad de los demás miembros constituyen elementos determinantes para alcanzar este propósito.

Los valores de sustentabilidad obtenidos confirman la existencia de una cierta racionalidad ecológica por parte del agricultor. La estrategia de buscar una alta biodiversidad en el agroecosistema coincide con lo que varios agroecólogos definen como una práctica sostenible (Gliessman, 2000; Altieri et al., 2007).

\subsection{Finca Patio Integral La Joya}

En el Cuadro 9 se presentan las principales características ecológicas.

Cuadro 9. Aspectos ecológicos patio integral Escuela La Joya

\begin{tabular}{ll}
\hline Se pueden apreciar disímiles asociaciones como la guayaba \\
asociada a condimentos y hortalizas, el plátano y varias especies \\
de frutales que ocupan estratos arbóreos y arbustivos, en \\
asociación también con otras especies de porte o hábitos \\
rastreros, con especies que soportan la sombra o requieren de \\
esta asociación, como por ejemplo mango, limón, café, ajo, plantas \\
repelentes y ornamentales visitadas por abejas. \\
Suelo encuentra dentro del agrupamiento Antrosoles. Tiene suelo del \\
tipo recultivado antrópico (Orihuela et al., 2007), con buena \\
fertilidad dado el amplio desarrollo que se observa en los cultivos. \\
Los valores de materia orgánica son altos. \\
El agua que se utiliza para el riego del patio es de la fuente de \\
abastecimiento "Clodomira" y es la misma que abastece a una \\
parte de la población lajera. El nitrato presentó una leve variación \\
y, mientras no aumente sus valores, no tiene restricción para el \\
uso agrícola. Los valores del pH y de la dureza se encuentran \\
entre los rangos permitidos por la normatividad nacional. \\
\hline Agua
\end{tabular}


Predominan las verduras de hojas, aunque produce también pepino, tomate, rábano, perejil, cilantro, entre otros. Dentro de las

Subsistema raíces, tubérculos y cormos, produce boniato, papa, yuca, ñame y agrícola plátano. También cuenta con algunos árboles frutales. La huerta cuenta con 189 variedades de plantas y el componente animal de crianza. Tiene en total 11 especies y el manejo que realiza favorece el control ecológico de plagas.

\begin{tabular}{ll}
\hline \multirow{2}{*}{$\begin{array}{c}\text { Subsistema } \\
\text { pecuario }\end{array}$} & Posenta con animales domésticos, fauna silvestre y entomofauna. \\
& ubicadas en dos puntos de la parcela. \\
\hline
\end{tabular}
Fuente: los autores.

La diversidad biológica de la parcela y el manejo que se le da por parte del productor favorece la estabilidad del sistema y la regulación biológica. La diversidad garantiza la disponibilidad permanente de alimento para la familia y la comercialización de productos frescos y libres de químicos durante todo el año.

Si se analiza el costo por peso de producción a partir de los resultados de un taller realizado con la participación del productor, estudiantes y un especialista en análisis económico, el costo de inversión es de 0.63 centavos por peso de producción.

El productor mantiene un registro sostenido de sus ingresos que asciende a cinco veces lo que en promedio recibe cualquier productor por hectárea/año, lo que demuestra la viabilidad del sistema. De estos ingresos, contribuye con un $10 \%$ al sistema tributario. El total de gasto cuantificable por año es de un tercio del total neto, mostrando con ello viabilidad económica.

Los costos de producción están relacionados con las compras de materia orgánica, el pago de la mano de obra, el uso de biofertilizantes y la adquisición de semillas certificadas no producibles en la parcela. El productor colabora socialmente con la comunidad enviando productos a muy bajo precios o gratuitos a un círculo infantil, un hogar materno y una escuela de niños discapacitados.

La vivienda de la familia tiene dos sistemas de páneles solares donados por el Ministerio de Agricultura al otorgarle la categoría "granja de excelencia nacional". Uno de los páneles está ubicado sobre el techo de la casa y provee energía a un grupo de electrodomésticos. Un segundo sistema se utiliza para la extracción y el bombeo de agua. El sistema de riego es por aspersión microjet, el cual es regulado mediante un programador de riego construido por el propio productor. Este invento vincula leyes físicas elementales que, conjugadas, forman un dispositivo que regula la frecuencia y el tiempo de riego según las exigencias del cultivo.

Para este agricultor y su familia, el patio les brinda el alimento diario. Los recursos económicos que genera la venta de sus productos aportan en la satisfacción de sus necesidades básicas, placer espiritual y beneficios no tangibles como el ambiente agradable y sano.

En el Cuadro 10 se presentan los indicadores de sostenibilidad de la finca La Joya y en la Figura 5 se presentan los resultados a través de la técnica gráfica "ameba". 
Cuadro 10. Indicadores de sostenibilidad del patio integral La Joya

\begin{tabular}{|c|c|c|c|}
\hline Dimensión & $\begin{array}{l}\text { Criterio de } \\
\text { diagnóstico }\end{array}$ & Indicador & $\begin{array}{l}\text { Valor del } \\
\text { indicador }\end{array}$ \\
\hline \multirow{16}{*}{$\begin{array}{l}\text { Biofisica- } \\
\text { Ambiental } \\
\text { (Ecológica) }\end{array}$} & \multirow{2}{*}{$\begin{array}{c}\text { Visión } \\
\text { integradora }\end{array}$} & Integración de uso de la tierra & 0.9 \\
\hline & & $\begin{array}{l}\text { Capacidad productiva del } \\
\text { agroecosistema }\end{array}$ & 0.9 \\
\hline & \multirow{3}{*}{ Suelos } & Fertilidad del suelo & 0.9 \\
\hline & & Medida en que se evita la degradación & 0.9 \\
\hline & & Productividad & 0.8 \\
\hline & \multirow{3}{*}{ Clima } & Tecnología del manejo del suelo & 0.9 \\
\hline & & $\begin{array}{l}\text { Combinación y distribución de los } \\
\text { elementos climáticos }\end{array}$ & 0.7 \\
\hline & & $\begin{array}{l}\text { Magnitud de las afectaciones por } \\
\text { eventos meteorológicos severos }\end{array}$ & 0.7 \\
\hline & \multirow{3}{*}{ Aguas } & $\begin{array}{l}\text { Manejo racional del recurso agua y la } \\
\text { cuenca }\end{array}$ & 0.8 \\
\hline & & $\begin{array}{l}\text { Disponibilidad y eficiencia de } \\
\text { utilización }\end{array}$ & 0.9 \\
\hline & & $\begin{array}{l}\text { Competencia entre consumo humano/ } \\
\text { agricultura }\end{array}$ & 0.7 \\
\hline & \multirow{3}{*}{ Biodiversidad } & Diversidad en el agroecosistema & 1 \\
\hline & & Diversidad de especies & 0.8 \\
\hline & & Diversidad genética & 0.8 \\
\hline & \multirow[b]{2}{*}{$\begin{array}{l}\text { Procesos } \\
\text { tecnológicos }\end{array}$} & Manejo de tecnologías novedosas & 0.9 \\
\hline & & $\begin{array}{l}\% \text { de autoabastecimiento con semillas } \\
\text { propias }\end{array}$ & 0.7 \\
\hline \multirow{12}{*}{$\begin{array}{l}\text { Económica- } \\
\text { Productiva } \\
\text { (Económica) }\end{array}$} & \multirow{3}{*}{$\begin{array}{l}\text { Productividad } \\
\text { económica }\end{array}$} & Estabilidad económica y productiva & 0.8 \\
\hline & & Eficiencia económica y productiva & 0.8 \\
\hline & & Productividad económica y productiva & 0.9 \\
\hline & \multirow{4}{*}{ Mercadotecnia } & Presencia del producto & 0.8 \\
\hline & & Relación costo-beneficio & 0.8 \\
\hline & & Distribución eficiente y equitativa & 1 \\
\hline & & Necesidad de intermediarios & 1 \\
\hline & \multirow{2}{*}{$\begin{array}{l}\text { Monitoreo de } \\
\text { insumos }\end{array}$} & Insumos a minimizar & 0.8 \\
\hline & & Insumos a optimizar & 1 \\
\hline & Infraestructura & Bienestar & 0.9 \\
\hline & \multirow[b]{2}{*}{ Energia } & Uso óptimo de la energía & 1 \\
\hline & & $\begin{array}{l}\text { Aprovechamiento máximo de energía } \\
\text { propia del sistema }\end{array}$ & 0.9 \\
\hline
\end{tabular}




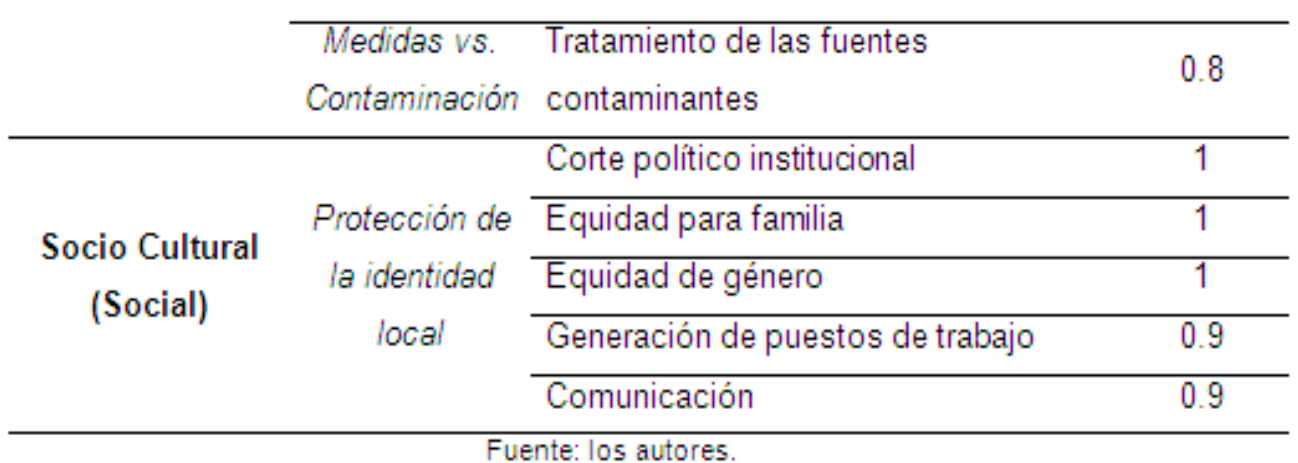

Fuente: los autores. 


\section{DIMENSIÓN ECOLÓGICA}

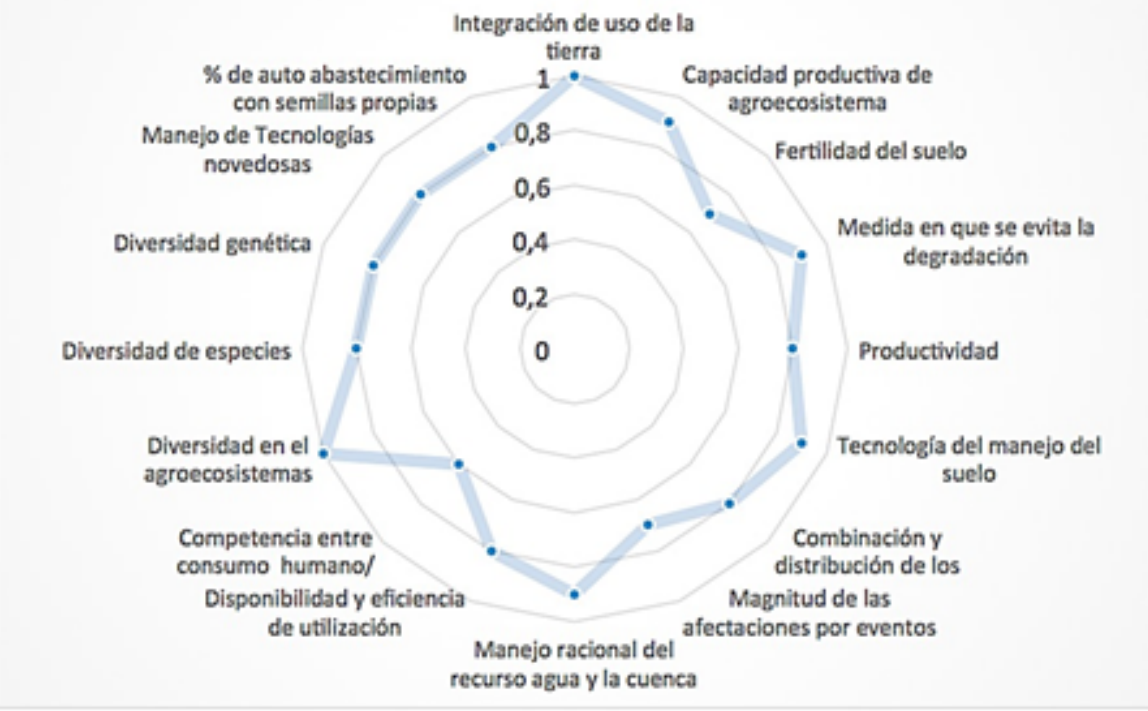

\section{DIMENSIÓN ECONÓMICA}

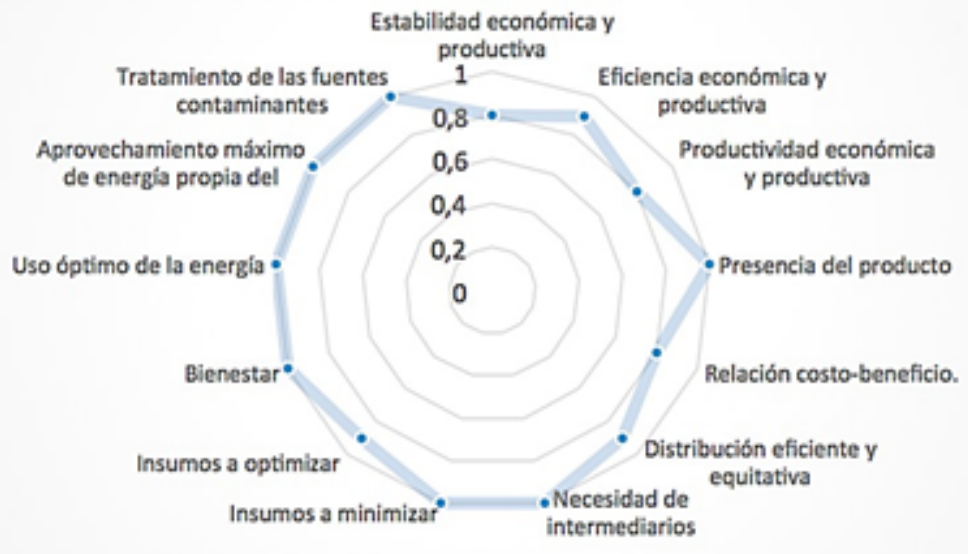

\section{DIMENSIÓN SOCIAL}

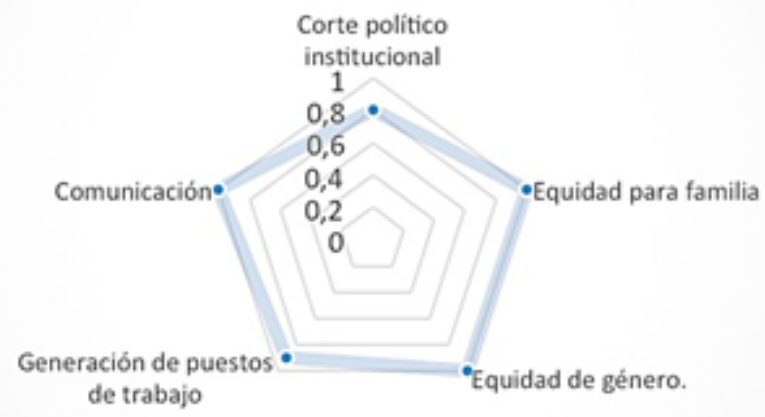

Fuente: los autores

Figura 5. Tendencias de la sostenibilidad del agroecosistema patio integral La Joya 
En el gráfico se puede observar que esta finca tiende a la sostenibilidad, ya que la mayor parte de los indicadores se acerca al borde y, siguiendo a Müller (1997), un sistema donde la mayor parte de los indicadores está cerca de alcanzar un valor meta puede ser considerado más sostenible que los sistemas donde los valores de sus indicadores son distantes.

El análisis mediante indicadores permite visualizar el alto nivel de sostenibilidad del sistema agrícola, ya que desarrolla su potencial productivo utilizando al máximo sus recursos internos. De esta forma, se ratifica lo que se percibe a simple vista: este agroecosistema ha logrado estabilidad económica, diversificación, productividad y eficiencia a través de años de utilización de tecnologías novedosas (como la creación de un programador de riego ecológico, cuya reproducción a escala internacional fue autorizada por el productor sin costo alguno), amplia diversidad biológica y manejo ecológico del suelo. Sin embargo, se observa que este sistema, como cualquier agroecosistema, es vulnerable a factores climáticos y, en ocasiones, se ve afectado por cambios drásticos de variables meteorológicas. Se presenta también competencia por el recurso agua entre el consumo familiar y los requerimientos agrícolas. Por otro lado, el tamaño de la parcela no admite el desarrollo del componente animal de especies mayores, por lo que ésta es una de las pocas técnicas que no puede desarrollar.

Por último, los indicadores de calidad del suelo se alejan un poco del límite adecuado, debido a la gran presión que se ejerce, ya que no se deja un tiempo prudente entre siembras para que el suelo se recupere de la extracción de nutrientes realizado por el cultivo anterior.

\subsection{Finca El Encanto}

En el Cuadro 11 se presentan las principales características ecológicas. 
Cuadro 11. Aspectos ecológicos de la finca El Encanto

\begin{tabular}{|c|c|}
\hline Diversidad & $\begin{array}{l}\text { Desde el punto de vista funcional se pueden diferenciar dos } \\
\text { subsistemas: el pecuario (ganado vacuno de leche, cerdos en } \\
\text { confinamiento para la ceba y aves de corral) y el agrícola, en el } \\
\text { que se encuentran cultivos asociados a árboles dispuestos como } \\
\text { cercas vivas, cortinas rompevientos y barreras para evitar la } \\
\text { erosión. La fauna espontánea o asociada a los cultivos es variada, } \\
\text { por lo que se supone el equilibrio relativo del sistema. }\end{array}$ \\
\hline Suelo & $\begin{array}{l}\text { Se clasifica, según Hernández et al. (2006), en el agrupamiento } \\
\text { fersialíticos pardo rojizos y rendzinas. Combinan las labores } \\
\text { mecanizadas y la tracción animal. Hay cobertura vegetal para } \\
\text { proteger el suelo de la erosión hídrica y la radiación solar directa. } \\
\text { Se observa el reciclado de nutrientes y la aplicación de estiércol } \\
\text { compostado. }\end{array}$ \\
\hline Agua & $\begin{array}{l}\text { Está limitado al sistema de acueducto del municipio y a la etapa de } \\
\text { lluvias. No existe posibilidad de riego con aguas subterráneas por } \\
\text { la ausencia de manantiales (Porta y López, 2005). Para mantener } \\
\text { la humedad del suelo realizan un manejo de coberturas. }\end{array}$ \\
\hline $\begin{array}{c}\text { Subsistema } \\
\text { agricola }\end{array}$ & $\begin{array}{l}\text { El objetivo es la producción de frutas como aguacate, mango, } \\
\text { guayaba, papaya y banano; y hortalizas como calabaza, ajo, } \\
\text { tomate, berenjena y cebolla. Se siembra también malanga, plátano, } \\
\text { maíz, frijol y boniato. Los que no son cultivos perennes se manejan } \\
\text { con rotación de cultivos, dependiendo de la época del año y las } \\
\text { necesidades de la comunidad. Como debilidad está el uso de } \\
\text { plaguicidas, aunque éstos se manejan limitadamente como } \\
\text { práctica de manejo integrado de plagas. }\end{array}$ \\
\hline $\begin{array}{c}\text { Subsistema } \\
\text { pecuario }\end{array}$ & $\begin{array}{l}\text { Cuenta con } 16 \text { cerdos al momento del diagnóstico. El objetivo de } \\
\text { este componente pecuario es el autoabastecimiento y la venta de } \\
\text { las crías sobrantes. También se registra la presencia de terneros } \\
\text { (5), añojos (6), novillas (4), toros (1), bueyes (2) y vacas (16). }\end{array}$ \\
\hline
\end{tabular}

La finca es rentable económicamente, según el criterio de los productores. Hay algunos momentos de menores ingresos, pero éstos se compensan con otros más productivos. No llevan registros contables de la producción, pero sostienen que la ganancia es de aproximadamente 34 centavos por peso. Es decir, que les cuesta 66 centavos producir un peso.

La producción está orientada al autoabastecimiento para dos familias, el mercado agropecuario local y la contribución social al hospital de San José, un hogar de niños sin amparo y una escuela primaria. Los principales gastos que se presentan son la compra de combustible diésel, pienso, fertilizante químico, plaguicidas sintéticos, productos biológicos y pago salarios. 
La finca cuenta con dos tractores e implementos como arado de disco, grada, tiller, cultivador, multiarado y una combinada para cosechar y separar los residuos de los granos, la cual fue confeccionada por los mismos propietarios.

En el Cuadro 12 se presentan los indicadores de sostenibilidad de la finca El Encanto y en la Figura 6 se presentan los resultados mediante la técnica gráfica "ameba".

Cuadro 12. Indicadores de sostenibilidad de la finca El Encanto

\begin{tabular}{|c|c|c|c|}
\hline Dimensión & $\begin{array}{l}\text { Criterio de } \\
\text { diagnóstico }\end{array}$ & Indicador & $\begin{array}{l}\text { Valor del } \\
\text { indicador }\end{array}$ \\
\hline \multirow{11}{*}{$\begin{array}{l}\text { Biofisica- } \\
\text { Ambiental } \\
\text { (Ecológica) }\end{array}$} & & Integración de uso de la tierra & 0.9 \\
\hline & integradora & $\begin{array}{l}\text { Capacidad productiva de } \\
\text { agroecosistema }\end{array}$ & 0.8 \\
\hline & \multirow{3}{*}{ Suelos } & Fertilidad del suelo & 0.8 \\
\hline & & Medida en que se evita la degradación & 0.9 \\
\hline & & Productividad & 0.9 \\
\hline & \multirow{3}{*}{ Clima } & Tecnología del manejo del suelo & 0.9 \\
\hline & & $\begin{array}{l}\text { Combinación y distribución de los } \\
\text { elementos climáticos }\end{array}$ & 0.7 \\
\hline & & $\begin{array}{l}\text { Magnitud de las afectaciones por } \\
\text { eventos meteorológicos severos }\end{array}$ & 0.8 \\
\hline & \multirow{3}{*}{ Aguas } & $\begin{array}{l}\text { Manejo racional del recurso agua y la } \\
\text { cuenca }\end{array}$ & 1 \\
\hline & & $\begin{array}{l}\text { Disponibilidad y eficiencia de } \\
\text { utilización }\end{array}$ & 0.6 \\
\hline & & $\begin{array}{l}\text { Competencia entre consumo humano/ } \\
\text { agricultura }\end{array}$ & 0.8 \\
\hline
\end{tabular}




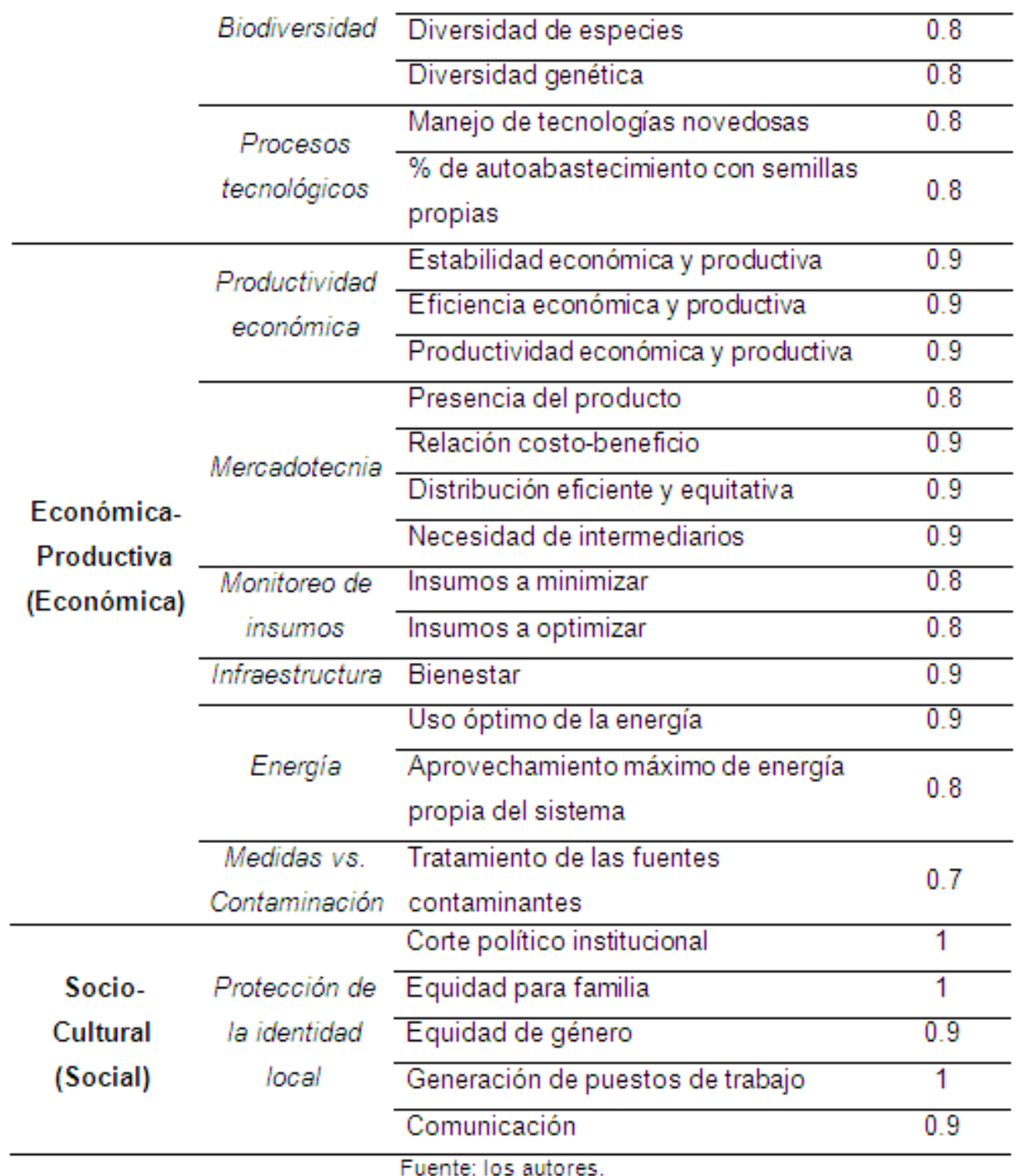




\section{DIMENSIÓN ECOLÓGICA}

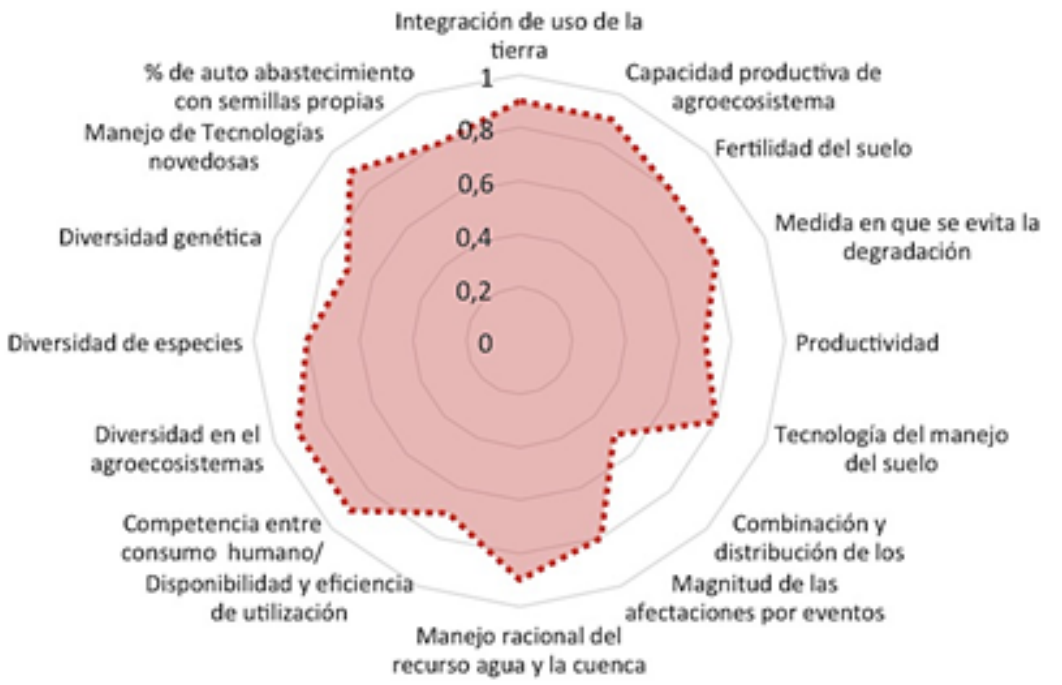

\section{DIMENSIÓN ECONÓMICA}

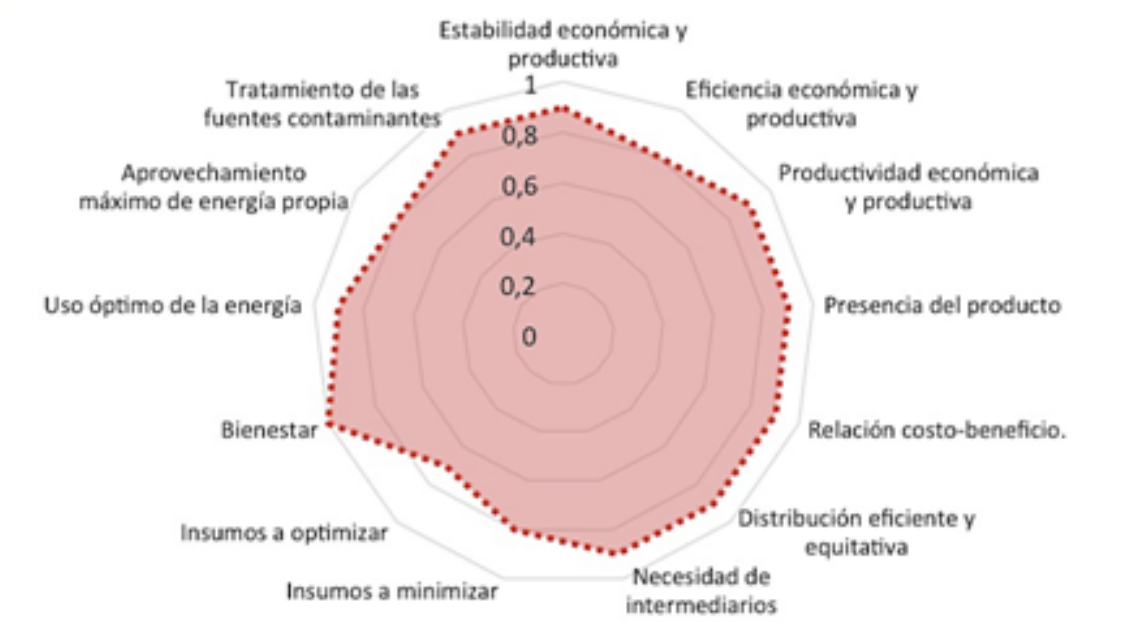

\section{DIMENSIÓN SOCIAL}

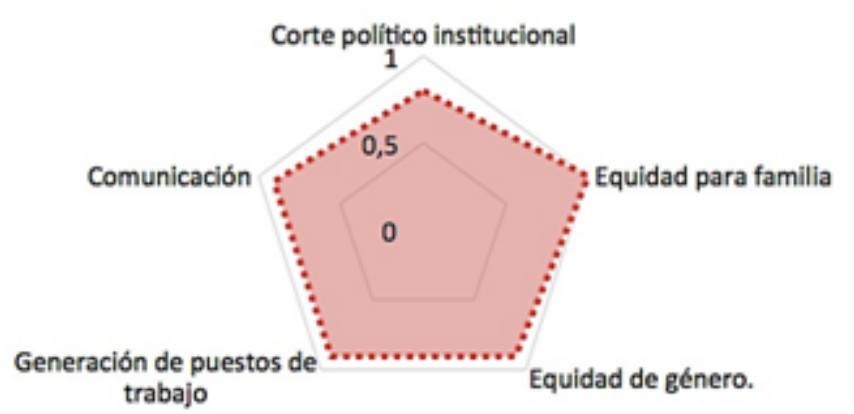

\section{Fuente: los autores}

Figura 6. Tendencias de la sostenibilidad del agroecosistema El Encanto 
La finca utiliza tecnologías de integración agroforestal que ha sabido manejar y renovar acorde con sus necesidades. Son agricultores tradicionales, pero están abiertos a nuevos conocimientos tecnológicos. Para ellos, aplicar fertilizantes orgánicos compostados es esencial, pero utilizan también fertilizantes químicos de una forma racional. Para la regulación de plagas aplican medios biológicos por inundación y pesticidas químicos sintéticos como última opción.

Durante todo el año los agricultores practican la rotación de cultivos, por lo que no generan una significativa degradación del suelo. Sin embargo, la finca presenta dificultades con el recurso agua ya que depende en su mayoría del régimen de lluvias, por tal razón es recomendable proyectar un sistema de riego que permita garantizar un acceso continuo a este recurso.

Por último, según los resultados del gráfico de la dimensión económica, se debe fortalecer la optimización de insumos, ya que esto repercute directamente en el rendimiento económico.

\section{5. Índice general de sostenibilidad de los agroecosistemas}

Para calcular este índice se aplicó la Ecuación 2 para cada una de las fincas (Figura 7).

\section{Acercamiento a la sostenibilidad}

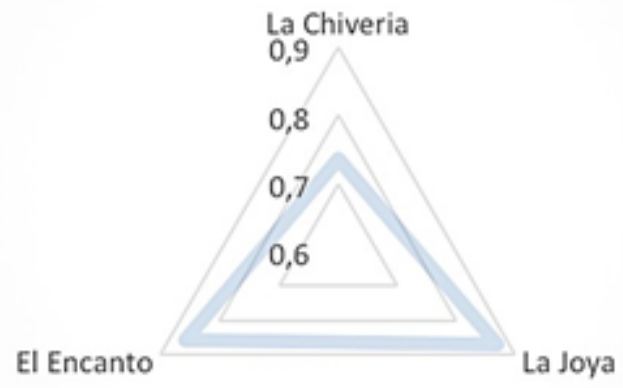

Fuente: los autores.

Figura 7. Sostenibilidad de los tres agroecosistemas estudiados

Según los datos obtenidos, el índice de sostenibilidad para el patio integral escuela "La Joya" es de 0.86. Esto es gracias a su trabajo agroecológico y a las óptimas condiciones ambientales del agroecosistema, tal como fue descrito por Orihuela et al. (2007). Para La Chivería, este índice es de 0.77 debido a sus potencialidades en el reconocimiento de la producción de semilla de alta calidad, reciclaje de nutrientes y uso eficiente de sus recursos. Finalmente, la finca El Encanto tiene un índice de 0.84 , el cual se acerca a la concepción de una finca sostenible, aunque debe ser estudiada con más profundidad por ser un sistema de secano que ha subsistido por más de 50 años. 


\section{CONCLUSIONES}

Los tres agroecosistemas seleccionados del municipio de San José de Las Lajas tienen particularidades marcadas que los diferencian entre sí, como por ejemplo sus objetivos productivos (propósito y producciones principales), las tecnologías que utilizan para ejecutar los procesos dentro del sistema y el nivel de documentación de sus actividades. No obstante, hay rasgos comunes que pueden ser llevados a escalas numéricas y agregados para confeccionar el set de indicadores.

Este estudio permitió evidenciar que los agricultores de las fincas seleccionadas están comprometidos con la implementación de prácticas agroecológicas que aportan a la sostenibilidad de sus procesos. De igual forma, su conocimiento resulta ser una herramienta conceptual útil para la toma de decisiones en el manejo de los sistemas de producción.

Los tres agroecosistemas, según el Índice General de Sostenibilidad, presentan un significativo nivel de sostenibilidad $(>0.7)$ gracias a las prácticas agrícolas hoy en día desarrolladas y a la alta evaluación relativa de las dimensiones ecológica, económica y social. La finca La Joya es la que presenta el mayor índice (0.86) como resultado de las actividades agroecológicas implementadas, el mayor grado de diversidad existente y el óptimo uso de la energía.

Si bien los tres agroecosistemas presentan altos índices de sostenibilidad, el presente estudio encontró debilidades y escenarios susceptibles de mejoramiento que, de ser atendidos, optimizarían los niveles de sostenibilidad de las fincas. De esta forma, La Chivería tiene el potencial de diversificar su producción con animales, lo que fomentaría el reciclado de nutrientes y, por lo tanto, la utilización de recursos propios de la finca. Puede aprovechar, además, el uso de energías alternativas para reducir el consumo de diésel. Por otro lado, la finca La Joya presenta debilidades de tipo administrativo al no disponer de registros contables, ni tener reconocido su papel como productor de semillas, lo que impide que sean certificadas. Finalmente, la finca El Encanto ejerce una fuerte presión sobre el suelo, ya que no se deja un tiempo prudente entre siembras para que el suelo se recupere de la extracción de nutrientes realizado por cultivos previos. De igual forma presenta debilidades en cuanto al suministro de agua, puesto que depende en su mayoría del régimen de lluvias.

Los resultados de la presente investigación pueden ser utilizados por los productores y decisores para trazar planes de mejoramiento con miras a proyectar estrategias en el municipio.

\section{AGRADECIMIENTOS}

Los autores expresan su agradecimiento a la Universidad Agraria de La Habana (Cuba) por abrir lazos de amistad y cooperación con países latinoamericanos. De igual forma, al secretariado y decano de la Facultad de Agronomía, y a los profesores Dr. Orestes Cruz, Dr. Saimel Fontes y Dr. Nelson Martín, de dicha universidad, por su gran apoyo en la realización del presente estudio. 
POTENCIAL CONFLICTO DE INTERESES

Este trabajo no tiene conflicto de intereses.

\section{REFERENCIAS}

- Altieri, M. (2002). Agroecología: Principios y estrategias para diseñar sistemas agrarios sustentables. En Agroecología: El camino hacia una agricultura sustentable. Buenos Aires (Argentina): E.C.A. Ediciones Científicas Americanas, pp. 27 - 34.

- Altieri, M. y Nicholls, C. (2000). Agroecología. Teoría y práctica para una agricultura sustentable. México D. F. (México): PNUMA.

- Altieri, M.; Ponti, L. y Nicholls, C. (2007). El manejo de plagas a través de la diversificación de las plantas. En: Revista de Agroecología 22(4), pp. 9-12.

- Astier, M. y Hollands, J. (2007). Sostenibilidad y campesinado. Seis experiencias agroecológicas en Latinoamérica. México D.F. (México): Mundiprensa, GIRA, ILEIA.

- Astier, M.; Maass, M. y Etchevers, J. (2002). Derivación de indicadores de calidad de suelos en el contexto de la agricultura sustentable. Agrociencia 36(5), pp. 605-620.

- Astier, M.; Masera, O. y Galván-Miyoshi, Y. (Coord.) (2008). Evaluación de sustentabilidad. Un enfoque dinámico y multidimensional. Valencia (España): SEAE/CIGA/ECOSUR/UNAM/Mundiprensa.

- Deckers, J.; Nachtergaele, F. y Spaargaren, F. (1998). World Reference Base for Soil Resources. Introduction. Leuven (Belgium): ISSS/ISRIC/FAO.

- FAO (2004). Aplicación de estrategias de desarrollo enfocadas hacia las personas en el ámbito de la FAO. Roma (Italia): Programa de Apoyo a los Modos de Vida Sostenibles (LSP).

- Funes, F. (2007). Agroecología, agricultura orgánica y sostenibilidad. La Habana: ACTAF.

- Funes, F.; García, L.; Bourque, M.; Pérez, N. y Rosset, P. (2001). Transformando el campo cubano. Avances de la agricultura sostenible. La Habana: ACTAF.

- Geilfus, F. (2002). 80 herramientas para el desarrollo participativo. Diagnóstico, planificación, monitoreo, evaluación. San José (Costa Rica): IICA.

- Gliessman, S. (2000). Agroecology: ecological process in sustainable agriculture. Florida (USA): CRC Press. 
- Hernández, A.; Morales, M.; Ascanio, M. y Morell, F. (2006). Manual práctico para la aplicación de la nueva versión de clasificación genética de los suelos de Cuba. [CD-ROM]. Sociedad Cubana de la Ciencia del Suelo / VI Congreso Nacional de la Ciencia del Suelo. La Habana, Cuba.

- Jiménez, R. (2007). Evolución del desarrollo de las cooperativas agrícolas cubanas: Retos y perspectivas. First International CIRIEC Research Conference on the Social Economy: Canadian Social Economy Hub.

- Leyva, A.; Alonso, A. y Vegas, J. (1999). La investigación participativa para el rescate, perfeccionamiento y aplicación de tecnologías apropiadas en la agricultura cubana. Informe final de proyecto. La Habana (Cuba): Instituto Nacional de Ciencias Agrícolas.

- Leyva, A. y Pohlan, J. (2005). Agroecología en el trópico - ejemplos de Cuba. La biodiversidad vegetal, cómo conservarla y multiplicarla. Aachen (Alemania): Ediciones Shaker Verlang.

- López-Ridaura, S.; Masera, O. y Astier, M. (2002). Evaluating the sustainability of complex socio-environmental systems. The MESMIS framework. Ecological Indicators 2(1), pp. 135-148.

- Masera, O., Astier, M. y López-Riadura, S. (1999). Sostenibilidad y manejo de recursos naturales. El marco de evaluación MESMIS. México D.F. (México): MundiPrensa, GIRA, UNAM.

- Masera, O. y López-Ridaura, S. (2000). Sostenibilidad y sistemas campesinos. Cinco experiencias de evaluación en el México rural. México D.F. (México): MundiPrensa, GIRA, UNAM.

- MINSAP (2001). Normas Cubanas. Sistema de Norma para determinar calidad química de agua potable. Requisitos y muestreo. NC 93-02 de 1986 "Agua potable, requisitos sanitarios y muestreos".

- Moreno, H.; Pedraza, G. y Solarte, A. (2006). Construcción y uso de indicadores de sostenibilidad para la Planeación Participativa de Predios [En línea]. Recuperado de URL: http://desarrollo.ecoportal.net/content/view/full/63022 [consulta: 17/04/2014].

- Müller, S. (1997). Evaluating the sustainability of agricultura. The case of the Reventado River Watershed in Costa Rica. European University Studies: Serie 5. Berlin (Germany): Peter Lang International Academic Publishers. 
- Oficina Nacional de Estadística (2010). Datos de población de la provincia de la Habana. Informe Nacional. La Habana (Cuba): Oficina Nacional de Estadística.

- Orihuela, J.; Peña, L.; Gutiérrez, W.; Burbano, M. y Jeans, L. (2007). Diagnóstico para el reconocimiento ambiental del patio integral escuela "La Joya". La Habana: UNAH y CEDAR.

- Pérez, N. (2003). Agricultura orgánica: bases para el manejo ecológico de plagas. La Habana: CEDAR, ACTAF, HIVOS.

- Porta, J. y López, M. (2005). Agenda de campo de suelos. Información de suelos para la agricultura y el medio ambiente. Barcelona: Ediciones Mundi-Prensa.

- Pretty, J. (1995). Regenering agriculture: policies and practice for sustainability and self - reliance. London (England): International Institute for Environment and Development.

- Red Leisa (2007). Agricultura sostenible. Ideas básicas y experiencias. Perú: Asociación ETC Andes y Fundación ILEIA.

- Ramírez, O. (2009). Riesgos de origen tecnológico: apuntes conceptuales para una definición, caracterización y reconocimiento de las perspectivas de estudio del riesgo tecnológico. RevistaLuna Azul 29, pp. 82-94.

- Reyes, R. y Ammour, T. (1997). Sostenibilidad de los sistemas de producción en la concesión comunitaria de San Miguel. Petén, Guatemala. Guatemala: Proyecto Conservación para el Desarrollo Sostenible en América Central.

- Rodríguez, C. (2007). Aspectos a considerar para el desarrollo de una agricultura sostenible en Cuba. La Habana (Cuba): Centro de Estudios de la Economía Cubana.

- Rosset, P. (1997). La crisis de la agricultura convencional, la sustitución de insumos y el enfoque agroecológico. Revista de Agroecología y Desarrollo (11/12), pp. 2-12.

- Sarandón, J.; Zuluaga, M.; Cieza, R.; Gómez, C.; Janjetic, L. y Negrete, E. (2006). Evaluación de la sostenibilidad de sistemas agrícolas de fincas en Misiones, Argentina, mediante el uso de indicadores. Revista de Agroecología 1, pp. 19-28.

- Schönhuth, M. y Kievelitz, U. (1994). Diagnóstico Rural Rápido Participativo: métodos participativos de diagnóstico y planificación en la cooperación al desarrollo. Alemania: Deutsche Gesellschaftfur Technische Zusammenarbeit - GTZ. 
- Sepúlveda, S. (2002). Desarrollo Sostenible Microrregional. En: Sepúlveda, S. y Edwards, R. (Comp.). Desarrollo Sostenible. Agricultura, Recursos Naturales y Desarrollo Rural. San José (Costa Rica): IICA, pp. 9-26.

- Socorro, A. (2002). Indicadores de la sostenibilidad de la gestión agraria en el territorio de la provincia Cienfuegos. Universidad Agraria de La Habana.

- THREAD (2005). Sembremos la semilla de los derechos: Examen del comercio agrícola y la OMC desde la perspectiva de los derechos humanos. Nota de antecedentes No. 1. Serie THREAD.

- Venegas, R. (2004). Indicadores de sostenibilidad predial. Revista de Agroecología y Desarrollo (11/12).

1. Ingeniera Agroforestal, Universidad Nacional Abierta y a Distancia UNAD,santamaria0610@yahoo.com. ORCID iD: 0000-0002-5540-5238.

2. Ingeniero Ambiental y Sanitario, Esp. Evaluación del Impacto Ambiental de Proyectos, MSc. Sistemas Ambientales Humanos, MSc. Tecnología Ambiental, estudiante de Doctorado en Ciencia y Tecnología Industrial y Ambiental. Grupo de Estudios Ambientales Aplicados - GEAA, Universidad Nacional Abierta y a Distancia UNAD, omar.ramirez@unad.edu.co. ORCID iD: 0000-0002-8594-5139.

3. Inicia a comienzos de los años noventa con la caída del campo socialista de la antigua Unión Soviética, con la cual Cuba mantenía fuertes lazos comerciales.

Para citar este artículo: Silva-Santamaría, L. y Ramírez-Hernández, O. (2017). Evaluación de agroecosistemas mediante indicadores de sostenibilidad en San José de las Lajas, provincia de Mayabeque, Cuba. Luna Azul, 44, 120-152. DOI: 10.17151/luaz.2017.44.8. de http://200.21.104.25/lunazul/index.php/component/content/article?id=224

Esta obra está bajo una Licencia de Creative Commons Reconocimiento CC BY

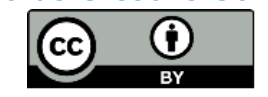

